\title{
Threats to Professional Roles in Part-Time Leadership
}

\section{Effects of Dysfunctional Support on Leader Identification, Rumination, and Job Satisfaction}

\author{
Mona Rynek ${ }^{1}$, Thomas Ellwart, Henrike Peiffer ${ }^{1}$, Elisabeth Endres², and Thomas Moldzio ${ }^{3}$ \\ 'Department of Psychology, Trier University, Germany \\ 2DZ PRIVATBANK S.A., Strassen, Luxembourg \\ ${ }^{3}$ Moldzio \& Partner - Institut für Personalauswahl, Ahrensburg, Germany
}

\begin{abstract}
Leaders working part time struggle with a lack of respect and acceptance from their subordinates and their management colleagues. Leadership as a part-time role does not match the traditional expectation of leaders being omnipresent and always responsive (Jochmann-Döhl, 2017). Although leaders working part time (LPT) are supported by subordinates and colleagues, their supportive behavior is often coupled with accusations that work-related problems occur only because the leader is working part time. According to the stress-asoffense-to-self theory (SOS, Semmer et al., 2007; Semmer et al., 2019), such dysfunctional supportive behavior triggers threats by offending the need for belonging. This study serves to strengthen SOS theory and extend its application beyond stress research by investigating the effects of LPT threat experiences on rumination, LPT job satisfaction, and role identification. Further, it empirically confirms the need-based threat mechanism. Results based on an online questionnaire $(N=101$ LPT) show that dysfunctional support by subordinates and management colleagues relates to a feeling of exclusion by significant others as an indicator of an offended need for belonging. Furthermore, the results indicate that the feeling of exclusion mediates the relationship between dysfunctional support and role identification and between dysfunctional support and LPT job satisfaction. No mediation effect was found for rumination. In addition to providing a theoretically differentiated understanding and prediction of threats, the study includes important practical starting points for the risk management of LPT.
\end{abstract}

Keywords: part-time leadership, threat, professional roles

Bedrohungen der beruflichen Rolle von reduziert arbeitenden Führungskräften. Effekte von dysfunktionaler Unterstützung auf Rollenidentifikation, Rumination und Arbeitszufriedenheit

Zusammenfassung: Führungskräfte, die reduziert arbeiten erfahren häufig wenig Respekt und Akzeptanz durch Mitarbeiter und Kollegen. In reduzierter Arbeitszeit zu Führen entspricht nicht dem traditionellen Rollenbild einer Führungskraft, die als Erste das Büro betritt und als Letzte verlässt (Jochmann-Döhl, 2017). Obwohl reduziert arbeitende Führungskräfte von ihren Mitarbeitern und Kollegen unterstützt werden, ist deren Unterstützungsverhalten oft mit dem Vorwurf verbunden, dass arbeitsbezogene Probleme nur deshalb auftreten, weil die Führungskraft reduziert arbeitet. Nach der Stress-as-offence-to-self Theorie (SOS, Semmer et al., 2007; Semmer et al., 2019) löst ein solch dysfunktionales Unterstützungsverhalten Bedrohungen aus, indem es das Bedürfnis nach Zugehörigkeit verletzt. Ziel der Studie ist es zum einen, die Bedeutung der SOS Theorie hervorzuheben und ihre Anwendung über die Stressforschung hinaus zu verdeutlichen, indem die Auswirkungen von Bedrohungserfahrungen auf Rumination, Arbeitszufriedenheit und Rollenidentifikation bei reduziert arbeitenden Führungskräften untersucht werden. Zum anderen zielt die Studie darauf ab, den bedürfnisbasierten Bedrohungsmechanismus empirisch zu bestätigen. Ergebnisse, die auf einer Online-Befragung von $N=101$ reduziert arbeitenden Führungskräften basieren, zeigen, dass dysfunktionale Unterstützung durch Mitarbeiter und Kollegen mit einem Gefühl der Ausgrenzung durch bedeutende Andere als Indikator für ein frustriertes Bedürfnis nach Zugehörigkeit zusammenhängt. Darüber hinaus zeigen die Ergebnisse, dass das Gefühl der Ausgrenzung die Beziehung zwischen dysfunktionaler Unterstützung und Rollenidentifikation sowie zwischen dysfunktionaler Unterstützung und Arbeitszufriedenheit vermittelt. Für Rumination wurde kein Mediationseffekt gefunden. Neben einem theoretisch differenzierten Verständnis und der Vorhersage von Bedrohungen liefert die Studie wichtige praktische Ansatzpunkte für das Risikomanagement von Führung in reduzierter Arbeitszeit.

Schlüsselwörter: Führung in reduzierter Arbeitszeit, Bedrohung, berufliche Rollen

"It is all or nothing. Part-time leadership is half leadership" (statement by the human resources director of an international bank). Leaders who work part time (LPT) may have to deal with such attitudes, which indicate a 
disrespect for LPT and result in negative emotional and cognitive states (Jochmann-Döll, 2017). Disrespectful statements stem from beliefs that leaders must be omnipresent and always responsive - an expectation not fulfilled by LPT. Moreover, empirical evidence shows that subordinates and full-time leaders alike believe that being an LPT results in more strain on the subordinates, vague decision-making processes, and ambiguous responsibilities (Moldzio et al., 2016). Unsurprisingly, some management colleagues and subordinates do not take LPT seriously, associate problems and mistakes to LPT (Moldzio \& Ellwart, 2017), or exclude LPT altogether (Jochmann-Döll, 2017). These negative associations, rejections, and other disrespectful behaviors toward LPT in the workplace trigger feelings of being questioned in the role as a leader; consequently, these LPT experience threats (cf., Sam, 2012).

According to proponents of the stress-as-offense-to-self theory (SOS, Semmer, Jacobshagen, Meier, \& Elfering, 2007), these negative associations, rejections, and disrespectful behaviors toward LPT may threaten these individuals' leadership position. Studies based on SOS postulate dysfunctional support - a kind of disrespectful behavior - as a trigger of threat (e.g., Semmer et al., 2007, 2008, 2019) and report stress-related consequences. Dysfunctional support may also act as a specific trigger in the context of LPT, for example, when subordinates mention that work-related problems occur only because the leader is working part time (cf., JochmannDöll, 2017). So far, there is no research on threats to LPT as leaders, though there are studies on threats to leaders in general. These studies show that, in addition to causing stress, a leader's feeling threatened by subordinates or colleagues may negatively affect the leader's motivation, affect, and performance (e.g., Burnette et al., 2010). This study goes beyond traditional stress research in strengthening support for SOS and investigates dysfunctional support (trigger) by subordinates or colleagues for LPT and the threatening effect of dysfunctional support on stress-related and other outcomes, such as leadership identification, job satisfaction, and rumination. Furthermore, this study addresses the threat mechanism that explains the underlying effect of triggers on outcomes. SOS (Semmer et al., 2007, 2019) explains this mechanism by referring to a frustrated need for belonging - to belong to a group and to be respected by significant others (Leary \& Baumeister, 2000). To our knowledge, only a few studies have investigated the mechanisms of (frustrated) needs in the relationship between triggers and outcomes (e.g., Stocker et al., 2010). Therefore, we investigate the threat mechanism and whether the effect of triggers on outcomes is mediated by frustrated needs (i.e., the need for belonging).
To this end, this study makes three important contributions: First, it extends the current research to include threats to LPT. Second, its investigation of the mediating role of frustrated needs provides evidence for the needbased threat mechanism postulated by SOS and, thus, enables a more differentiated understanding and prediction of threat experiences. Third, in addition to these theoretical contributions, this study derives conclusions for the practical risk management of LPT.

\section{The Professional Role as an LPT: Half the Time - Half the Value?}

In a representative survey of 500 leaders from Germany, $75 \%$ of the sample reported a preference for working part time in certain phases of their lives, for example, when caring for children (Borghardt, 2012a). During a shortage of skilled workers, the challenge of finding qualified management staff becomes increasingly greater (Maznevski et al., 2013), so that organizations become more sensitive to individual situations and needs. In this regard, flexible working-time models, such as part-time jobs, become instruments of human resource management. Part-time leadership describes various forms of workingtime models, such as reduced time (e.g., working only $80 \%$ of the full-time equivalent) in a leadership position (Moldzio \& Ellwart, 2017). In some leadership models, where leaders have reduced working hours, tasks are delegated to subordinates or are assumed by coleaders (Ellwart et al., 2015). Some leaders may reduce their working hours to have time not only for childcare but also to participate in other projects or advanced training (Moldzio et al., 2016). Thus, various working-time leadership models enable individuals to care for children and family members or to promote their career (e.g., by providing time for advanced training or alternative project work).

Even if many leaders are interested in working part time, the results of the European Labour Force Survey (2014, as cited in Stuth \& Hipp, 2017, p. 34) show that only $9 \%$ of the participating leaders actually work part time. One reason for this finding might be that LPT often have to struggle with negative reactions from others (e.g., low acceptance). LPT may not match the traditional expectation regarding leadership held by management colleagues or subordinates for several reasons: First, many organizations have a culture of presence, and only leaders who are constantly present are trusted to manage work processes successfully (Hipp \& Stuth, 2013). The widespread stereotype that a leader must be omnipresent does 
not fit the new working-time leadership model of LPT because, based on this stereotype, reduced working hours and professional commitment are a contradiction in terms. Only those who work the whole day - even beyond their duties - might have a strong commitment to their jobs and the organization (Melchers \& Zölch, 2001). Unsurprisingly, LPT are labeled as being insufficiently committed and underperformers (Brett \& Stroh, 2003). Second, there is the widespread but biased assumption that leadership responsibilities are neither shareable (i.e., by two leaders) nor delegable (Melchers \& Zölch, 2001). The reduced contact time for formal and informal communication with subordinates might negatively affect the trust and commitment extended to the LPT. Moreover, subordinates who prefer a full-time leader feel distant from the LPT goals and values, thus resulting in a lower acceptance of everything related to the LPT (Alberternst \& Moser, 2007). Consequently, LPT are often accused (justifiably or not) of being unable to fulfill their leadership responsibilities. In conclusion, there is ample evidence that management colleagues or subordinates react disrespectfully and express a lack of acceptance and respect toward their LPT (e.g., Moldzio \& Ellwart, 2017). The perception of a lack of acceptance and respect, i.e., experiences of disrespect, is related to the experience of threat (Semmer et al., 2007, 2019).

Although, to our knowledge, research on LPT and threats is lacking, there is some research available on leaders in general. For example, Burnette et al. (2010) showed that women in their role as leaders assessed their self-efficacy and self-esteem as being lower after experiencing threats from subordinates and colleagues. Likewise, Flanagan (2015), who also investigated women in leadership roles, postulated negative effects of threat experiences triggered by negative stereotypes of female leaders. The author found that women who feel threatened as leaders assess their ability to control their own career success significantly lower than do women who do not feel threatened as leaders. This could, on the one hand, support the idea of a double stigma of women in LPT. Women in full-time leadership positions often struggle to receive respect in general (Elprana et al., 2016), perhaps because female stereotypes do not correspond to those of leaders (Koenig et al., 2011). While men are described with agentic traits, women are seen as more "communal." Therefore, men are seen as more similar than women to the leader's stereotype of being competitive, confident, and strong (Rudman \& Mescher, 2013). The incongruity between the stereotypes of women and leaders may explain particular threat experiences of women in part-time leadership positions. On the other hand, even though LPT are often female (Stuth \& Hipp, 2017), it is likely that men who reduce work to their leadership positions also experience threats - even more than women. For example, studies that examine parental leave in fathers indicate that men who behave stereotypically-incongruently are generally seen as worse workers (Wayne \& Codeiro, 2003) and more ineligible for rewards (Allen \& Russell, 1999), compared to women who take parental leave or men who do not take parental leave. Gender-related stereotypes in LPT might be a further relevant facet in threat research.

In sum, threat research concerning leadership, especially LPT, is rare. Even if the effects of threat on professional leadership are evident, the theoretical framework for explaining threat originally comes from stress research.

\section{Threat by Disrespect: SOS Theory as a Guiding Framework}

According to SOS (Semmer et al., 2007, 2019), behaviors indicating a lack of respect do not directly cause threats. Rather, potential disrespectful behaviors from others serve as triggers perceived as representing one's exclusion from a relevant group (e.g., peers or colleagues). In this case, triggers offend the basic human need for belonging to significant others. The need for belonging describes the desire to be accepted and respected (Leary \& Baumeister, 2000). Based on the assumptions of SOS, disrespectful behaviors indicate that LPT are not accepted as fully qualified. LPT may perceive themselves as being excluded from colleagues and followers; this exclusion, in turn, threatens the need of LPT to belong. Thus, threats to the professional role as a leader occur.

Only a few studies have investigated the need-based mechanism. In a sample of officers from the Swiss army, Stocker and colleagues (2010) showed that disrespect leads to the perception of being less accepted and appreciated by others, thus resulting in low well-being, low job satisfaction, and feelings of resentment. Perceptions of low acceptance and appreciation by significant others, in turn, indicate a frustrated need for belonging (Leary \& Baumeister, 2000). There are different kinds of expressing appreciation and respect or disrespect (Stocker et al., 2014). Thus, Meier and Semmer (2018), for example, operationalized unreasonable or unnecessary task assignments (illegitimate tasks) as a trigger of threats. Dysfunctional support represents also an important trigger because of the disrespectful characteristics of this type of support (Semmer et al., 2008). Some studies on LPT examined the relationship between illegitimate tasks and work interruptions as potential triggers and a 
frustrated need for belonging; however, so far, none of these studies has examined the relationship between this need and dysfunctional support as a trigger.

\section{Dysfunctional Support and Perceived Exclusion in LPT: Mechanisms and Effects}

Semmer and colleagues $(2007,2008)$ introduced the concept of dysfunctional support as one of several behaviors indicating a lack of appreciation and respect. The authors found that, if functionally supportive behavior (e.g., giving someone important information) is coupled with dysfunctional reproaches and premature solutions, people experience threat, which affects their self-esteem or well-being (Semmer et al., 2008). In the context of LPT, dysfunctional support means, for example, that subordinates help LPT but accompany this help with accusations because of the reduced working hours of the leader seeking help. These behaviors indicate disrespect and express low acceptance of LPT as leaders. Similarly, if others expect special gratitude from supported LPT, dysfunctional behavior may cause a threat because such behavior suggests to LPT that they do not meet the requirements of the leadership role and therefore need support. However, if such dysfunctional behaviors cause the perception of being excluded as the leader - or more specifically if dysfunctional support offends the LPT's need to belong to a group of leaders and their followers the LPT experience threat. We refer to this perception as "perceived exclusion as a leader because of being an LPT" and postulate that high levels of dysfunctional support should be associated with a high perception of exclusion.

Hypothesis 1: Dysfunctional support of LPT is positively related to their perceived exclusion as a leader.

So far, research has investigated many stress- and health-related outcomes concerning threat experiences (e.g., Beals \& Peplau, 2005; Muller \& Butera, 2007). To take care of employees' well-being is an organizational issue to achieve high performance (Nielsen et al., 2017). In addition, research shows that identification with the professional role influences the motivation and performance of employees (cf. Ebaugh, 1988). Thus, the role identification of employees is also a central factor in organizations. There is evidence that threat has negative effects not only on well-being (Beals \& Peplau, 2005) but also on role identification (Petriglieri, 2011). Since LPT experience threats at work related to their role as leaders, in this study, we investigate the effect of threat on role identification and, in accordance with previous research, on stress-related symptoms, namely, on job satisfaction and rumination.

Role Identification. Organizational roles, such as leadership roles, are more variable than roles based on sex or race (Sluss et al., 2002). We describe role identification as the extent to which individuals are able (or motivated) to assume a role, such as the role of a leader in an organization. From an organizational point of view, low role identification or even a role exit (Petriglieri, 2011) is most critical because the individual disengages psychologically from the role and physically from its social relations or the related context at the workplace (Ebaugh, 1988). Case studies support the view that acceptance and support by subordinates are the strongest drivers of the successful introduction of part-time leadership (e.g., Meyenberg \& Schinner, 2017). Therefore, LPT who are supported and respected by their subordinates report higher identification with their role as a leader. Conversely, we expect high levels of dysfunctional support to be associated with a reduced role identification of LPT.

Hypothesis 2a: Dysfunctional support of LPT is negatively related to role identification as a leader.

Concerning the threat mechanism, dysfunctional support indicates a lack of respect and offends the individual need for belonging. Thus, perceived exclusion explains the effect of dysfunctional behavior on doubts about one's role as a leader.

Hypothesis 2b: Perceived exclusion because of LPT mediates the relationship between dysfunctional support and role identification as a leader.

Job Satisfaction. Blincoe and Harris (2011) found that disrespectful behaviors lead to a frustrated need for belonging and, therefore, to negative emotions. Moreover, threat is related to feelings of disappointment and dissatisfaction (Coyle, 1999). In an interview study ( $N=$ 41), Coyle (1999) identified several threats, such as the disrespectful behaviors of others, that produce dissatisfaction of patients in general health care. Likewise, Stocker and colleagues (2014) showed that recognition of success and support, which reflects the respectful behavior of others, correlates positively with increased satisfaction. The authors concluded that, conversely, experiencing disrespectful behavior is likely related to lower job satisfaction.

From these results, we deduce that LPT also experience dissatisfaction when facing threats in their role as a leader. We assume that high levels of dysfunctional support relate to reduced job satisfaction.

Hypothesis 3a: Dysfunctional support of LPT is negatively related to job satisfaction.

Job satisfaction is closely linked to fulfilled individual needs (e.g., Miller \& Monge, 1986). Herzberg (1972) 
emphasized the importance of motivators, such as a sense of being respected in an organization, in creating positive job satisfaction. Recent studies revealed a link between dissatisfaction and offended needs (Unanue et al., 2017). Therefore, we assume that the connection between dysfunctional support and lower job satisfaction can be explained by frustrated needs.

Hypothesis 3b: Perceived exclusion because of LPT mediates the relationship between dysfunctional support and job satisfaction.

Work-Related Rumination. Rumination means that it is difficult for people to stop worrying about work-related concerns after work, and that they are often preoccupied with professional matters and thoughts even at home (Cropley et al., 2012). Muller and Butera (2007) suggest that threat leads to ruminative thoughts. Moreover, studies indicate that facing disrespectful behavior by others is associated with ruminative behavior. For example, Vahle-Hinz et al. (2019) showed that workplace incivility (disrespectful behavior) is correlated with ruminative thoughts.

We assume that dysfunctional support relates to rumination among LPT. First, the necessity of support may indicate that leadership cannot be accomplished without the help of others. This may be accompanied by increased rumination over how to deal with work-related problems and one's own difficulties. Second, as discussed above, dysfunctional support offends the need for belonging. Concerning the threat mechanism, the perception of exclusion and lack of respect would also explain the rumination of LPT.

Hypothesis 4a: Dysfunctional support of LPT is positively related to rumination.

Hypothesis 4b: Perceived exclusion because of LPT mediates the relationship between dysfunctional support and rumination.

\section{Method}

\section{Participants and Procedure}

101 LPT completed an online questionnaire. The respondents worked in 21 different fields (e.g., finance, automobile industry, wholesale and retail, public services, media, science), represented all management levels, and had a mean leadership experience of 11.5 years $(S D=8.82)$. The participants' mean age was $M=46.59$ years $(S D=8.71$, range: 23 to 66 years). $78.2 \%$ of the participants were female. Working times in the leadership position varied between $20 \%$ and $90 \%$ with a mean of $66.74 \%$ of a fulltime equivalent $(S D=17.21) .53 .3 \%$ of the participants had reduced their working time for childcare and $12.9 \%$ for a better work-life balance. $2 \%$ of the leaders had reduced their working time for caring for family members, $4 \%$ for a flexible retirement model, and $3 \%$ for participating in advanced training; $24.8 \%$ gave other motives for reducing their working time. Leaders were responsible for 1 to 102 subordinates (control span) and had a mean of 13.05 subordinates. Concerning the hierarchical leadership level, $30.7 \%$ worked at a low level (i.e., responsible for teams and project groups), $42.7 \%$ at a middle level (i.e., responsible for department, subject area), and $26.7 \%$ at a high level (i.e., executive or divisional management). Regarding the flexible working-time model, $23.8 \%$ of the sample had reduced work time in the leadership position and taken on projects and activities in other areas of the company in a nonleadership position; $77 \%$ of the sample had worked in part-time leadership models and had held no other positions at the organization. The participants were recruited through advertisements in print and online media and through social networks with a special focus on LPT.

Before their participation, participants received information about the purpose, procedure, duration, and the voluntary nature of the study. All participants were informed that the data collected would not allow any conclusions to be drawn about the company or the individual. Before participating in the survey, the participants agreed that the anonymized data be used for scientific purposes. Cash prizes (4 x EUR 25) were randomly awarded to the participants after the survey.

\section{Instruments}

The participants rated all responses on a 5-point Likert scale, ranging from 1 (strongly disagree) to 5 (strongly agree). All items used in the questionnaire can be requested from the corresponding author.

Dysfunctional Support. Five items measuring dysfunctional support were adapted to the context of LPT from the scale developed by Semmer (2010). Items refer to different aspects of dysfunctional support, for example, giving help accompanied by accusations ("Because I work reduced working hours as a leader, social support is often associated with accusations") or the expectation of gratitude ("I get help at work when I need it, but because I am an LPT, sometimes special gratitude is expected"). The reliability of the five items was very good $(\alpha=.86)$. 
Perceived Exclusion as a Leader. Items that measured perceived exclusion as a leader ${ }^{1}$ reflect the perception of lacking acceptance and of disrespect by colleagues and subordinates due to being an LPT ("Some of the employees do not accept LPT such as full-time leaders"). The reliability of the four items was very good $(\alpha=.86)$.

Role Identification as a Leader. Four items of role identification ${ }^{1}$ ask respondents for their personal belief regarding whether they are equal to full-time leaders, i.e., whether they belong to the group of leaders or are an "oddball" (e.g., "As an LPT, I'm an oddball."). The reliability of the five items was good $(\alpha=.76)$.

Job Satisfaction. Four items were used to measure job satisfaction as an LPT. The items were adapted from validated scales (e.g., Weiss et al., 1967) and reflected the degree of satisfaction with the work situation as an LPT (e.g., "I am currently satisfied with my work situation.") or behavioral indicators of satisfaction ("I would recommend other leaders to work as LPT"). The reliability of the four items was good $(\alpha=.75)$.

Rumination. Three items of the Work-Related Rumination Questionnaire (WRRQ) were used to measure affective, problem-related, and distancing components of rumination (Cropley et al., 2012). An example item is "It is easy for me to relax after work." The reliability of the three items was acceptable $(\alpha=.63)$.

\section{Statistical Analysis}

We applied the statistical package of MPlus 8 (Muthén \& Muthén, 1998-2014). Using confirmatory factor analysis (CFA), we analyzed the internal structure of dysfunctional support and perceived exclusion to show that they represent independent constructs. We, therefore, compared the properties of two structural models: Model 1 represents a first-order correlated factor model and contains two different but correlated factors that correspond to dysfunctional support and perceived exclusion. We compared the first-order correlated factor model with a g-factor model (Model 2), where all items load only on a single general factor ( $g$-factor). We hypothesized that Model 1 fits the data better than Model 2. In both CFAs, we specified dysfunctional support, perceived exclusion, and the $g$-factor as latent variables. To handle convergence problems, we fixed the unstandardized loading of the first item of each first-order factor to 1 (Model 1 to
Model 2) and then evaluated both structural models based on different fit indices. We followed Kline (2011), Hu and Bentler (1999), and Dimitrov (2010) by evaluating the chi-square goodness-of-fit, comparative fit index (CFI), Tucker-Lewis index (TLI) (the values for both models should be above .95), root-mean-square error of approximation (RMSEA), standardized root mean squared residual (SRMR) (the values for both Model 1 and Model 2 should be below .08 and .06, respectively), Akaike information criterion (AIC), and Bayesian information criterion (BIC). To address missing data, we carried out the data analysis using full information maximum likelihood (FIML) estimation, which produces more efficient estimates than other methods (e.g., listwise deletion) of treating missing data and is, therefore, superior (Enders \& Bandalos, 2001). The number of missing data was below $5 \%$ for all scales.

To test the hypotheses, we separately conducted a mediation model for each of the three outcomes (role identification, job satisfaction, and rumination) by using dysfunctional support as an independent variable and perceived exclusion as a mediator. We used the nonparametric bootstrapping analyses macro by Preacher and Hayes (2004, 2008). Bootstrapping analyses are suited for smaller samples and do not impose the assumption of normality on the sampling distribution (Hayes, 2013). In detail, within the bootstrap test, we repeated the estimation of our structural models 5,000 times. The mediator effect is significant if the $95 \%$ bias-corrected and accelerated confidence interval (BCa CI) for the indirect effect does not include zero (Hayes, 2013).

\section{Results}

\section{Preliminary Analyses}

The CFAs revealed that dysfunctional support and perceived exclusion form distinct constructs. As expected, Model 1, with two distinct latent factors, provided a better fit than Model 2, with only one $g$-factor. Table 1 gives an overview of the two structural models and their corresponding goodness-of-fit indices. All model estimations terminated normally, no parameter estimates had negative variances, and all matrices of parameter estimates were positive. None of the two models exhibited poor

\footnotetext{
There are no scales in prior research that perceived exclusion as a leader or role identification. Therefore, LPT experts (consultants, researchers, $N=5$ ) developed items based on theoretical definitions. The fit of the items to the corresponding construct was verified by cognitive interviews (e.g., Drennan, 2003). To differentiate statistically between dysfunctional support (independent variable) and perceived exclusion (mediator), we conducted a confirmatory factor analysis (CFA, see preliminary analyses). The psychometric properties of the dependent variables (role identification, job satisfaction, and rumination) were assessed according to Schmidt-Atzert and Amelang (2012).
} 
Table 1. Goodness-of-fit indices of alternative CFA models

\begin{tabular}{lcccccccc}
\hline Model & $\chi^{2}$ & $d f$ & CFI & TLI & RMSEA & SRMR & AIC & BIC \\
\hline 1: First-order correlated factor & 48.291 & 26 & .942 & .919 & .092 & .053 & 2373 & 2446 \\
2: g-factor & 68.230 & 27 & .892 & .856 & .123 & .063 & 2398 & 2469 \\
\hline
\end{tabular}

Note. $\chi^{2}=$ chi-square for all models is $p<.01 ; d f=$ degrees of freedom; CFI = comparative fit index; TLI = Tucker-Lewis index; RMSEA = root-mean-square error of approximation; SRMR = standardized root-mean-square residual; $\mathrm{AIC}=$ Akaike information criterion; BIC = Bayesian information criterion.

Table 2. Descriptive statistics and correlations

\begin{tabular}{|c|c|c|c|c|c|c|c|c|c|}
\hline Scale & $M$ & $S D$ & Min & Max & 1 & 2 & 3 & 4 & 5 \\
\hline 1 Dysfunctional support & 2.25 & 0.90 & 1.00 & 5.00 & .86 & & & & \\
\hline 2 Perceived exclusion & 2.17 & 1.00 & 1.00 & 5.00 & $.72 * \star$ & .86 & & & \\
\hline 3 Role identification & 3.99 & 0.88 & 1.50 & 5.00 & $-.38 * \star$ & $-.47 * \star$ & .76 & & \\
\hline 4 Job satisfaction & 3.63 & 0.85 & 1.50 & 5.00 & $-.56 * \star$ & $-.59 * \star$ & $.35 \star \star$ & .75 & \\
\hline 5 Rumination & 2.81 & 0.86 & 1.00 & 5.00 & $.35 * \star$ & $.33 * \star$ & -.16 & $-.51 \star \star$ & .63 \\
\hline 6 LPT working hours & 66.74 & 17.21 & 20 & 90 & $-.42 * \star$ & $-.40 * *$ & $.32 * \star$ & $.27 * \star$ & $-.26 * *$ \\
\hline
\end{tabular}

Note. $M=$ mean, $S D=$ standard deviation, Min = Minimum, Max = Maximum. Bold values on the main diagonal denote Cronbach's a as measures of internal consistency. ${ }^{\star *} p<.001$.

model fit, although the chi-square goodness-of-fit statistic was statistically significant for each model. Evaluating both structural models regarding alternative fit indices, the first-order factor model (Model 1), compared to Model 2 , returned better incremental fit indices $\left(X^{2}=48.291\right.$, CFI $=.942$, TLI $=.919)$, good absolute model fit indices $($ RMSEA $=.092$; SRMR $=.053)$, and lower relative model fit indices of the AIC and BIC.

The validity of the LPT-specific measures can be illustrated by their sensitivity to the degree of workingtime reduction. Correlations showed that LPT whose working times were similar to those of full-time leaders report lower dysfunctional support $(r=-.42, p<.001)$, lower perceived exclusion $(r=-.40, p<.001)$, higher role identification $(r=.32, p<.001)$, higher job satisfaction $(r=$ $.27, p<.001)$, and lower rumination $(r=-.26, p<.001)$.

\section{Hypotheses Testing}

Hypothesis 1 confirms that dysfunctional support is positively related to perceived exclusion because of being an LPT in the workplace. Results from bivariate correlations in Table $2(r=.72, p<.001)$ and separate mediations (see Figure 1) indicate that dysfunctional support acts as a trigger that offends the need for belonging.

According to Hypothesis 2a, higher dysfunctional support is related to lower role identification $(r=-.38, p<.01)$. Moreover, perceived exclusion because of being an LPT mediates the relationship between dysfunctional support and role identification (Hypothesis $2 b$ ). As Figure 1 shows, we found a significant indirect effect of dysfunctional support on role identification $(b=-.29,99 \% \mathrm{BCa}$ CI[-.6018, -.0148]).

Hypothesis 3a is also confirmed: Higher dysfunctional support relates to lower job satisfaction in a bivariate correlation $(r=-.56, p<.01)$. In accordance with Hypothesis $3 b$, there is evidence for the mediating effect of perceived exclusion $(b=-.26,99 \%$ BCa CI[-.4798, $-.0590])$.

Finally, confirming Hypothesis 4a, LPT who receive more dysfunctional support report more rumination after work $(r=.35, p<.001)$. However, Hypothesis $4 \mathrm{~b}$ is rejected: Perceived exclusion does not explain the effect on rumination, as indicated by the confidence interval containing zero $(b=.12,95 \% \mathrm{CI}[-.0789, .3213])$.

\section{Discussion}

Using a sample of LPT, this study revealed the relationship between dysfunctional support and perceived exclusion as a leader. Moreover, correlations exist between dysfunctional support and three outcomes: role identification, LPT job satisfaction, and rumination. High levels of dysfunctional support are associated with identification problems with the leader role, reduced job satisfaction, and higher levels of rumination after work. Furthermore, the results show that the perception of being excluded by others because of being an LPT mediates the relationship between dysfunctional support and role identification, 


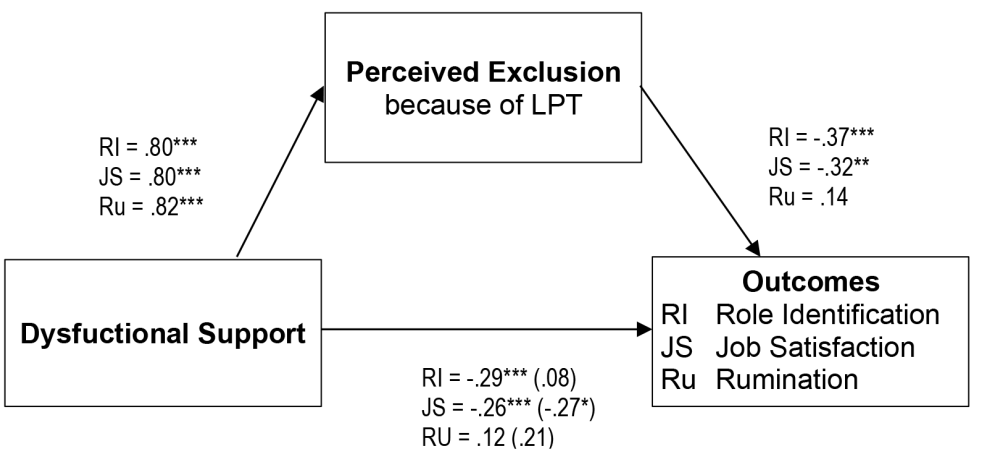

Note. ${ }^{*} p<.05,{ }^{* *} p<.01,{ }^{* * *} p<.001$.

Figure 1. Indirect and direct effects in parentheses from mediation analyses. and between dysfunctional support and job satisfaction. We found no mediating effect for rumination.

Our results are in line with the assumptions of the SOS (Semmer et al., 2007, 2019). In a sample of nonfaculty employees, Beehr et al. (2010) found that dysfunctional support has far-reaching psychological and even physical consequences. Meta-analytical findings by Kurtessis et al. (2017) prove that the perceived support in an organization harms identification processes and motivational parameters, as is also the case in our study. This study provides further evidence that a lack of respect, for example, through dysfunctional support, is a problem not only for subordinates but also for leaders (cf., Stocker et al., 2014).

A special focus of this study was the distinction between dysfunctional support as a trigger and the offended need for belonging. This study transfers the interplay between triggers and frustrated needs to the context of LPT, with perceived exclusion serving as a mediating mechanism concerning role identification and LPT job satisfaction. The perception that others do not respect and accept one another is decisive in assessing supportive behavior as helpful or not (Semmer et al., 2008). Beyond the degree of functional help, it is the message of disrespect and low acceptance of part-time leadership that is emotionally evaluated by the LPT. The oncoming frustrated need for belonging explains LPTrelated outcomes, such as lower role identification or lower job satisfaction. However, we could not confirm the mediating role of perceived exclusion in the relationship between dysfunctional support and rumination. In our study, rumination generally referred to the ability to switch off and relax after work, which are labor-related thoughts in general and are not specifically related to the professional role of a leader. Indeed, the sense of belonging seems to influence role-related variables (e.g., "In my role as LPT I feel excluded at work") rather than laborrelated thoughts in general (e.g., "I have a lot to do at work"). Being dependent on help alone can lead to stronger rumination. This consideration is supported by study results supporting the mediating role of perceived acceptance in the relationship between illegitimate tasks (e.g., the engineer must wipe the tables in the office and make coffee) and mainly role-related affective variables, such as resentment and job satisfaction (cf., Semmer et al., 2010).

\section{Limitations}

Despite its strengths, the present study has some limitations, primarily concerning the measurement methods and the investigation design. We operationalized the threatening trigger (dysfunctional support) and the frustrated need (perceived exclusion), both in relation to the LPT role. This led to a mediator that seems conceptually close to the predictor $(r=.72)$. Nevertheless, preliminary results indicate the distinction between the two constructs. Although we theoretically argue that the frustrated needs are role-related, future measures need to be more distinctive between triggers and needs. We suggest capturing directly the actual need and the level of frustration (e.g., "I feel that excluded"). Furthermore, all measures are self-reports with partly newly developed scales. We used inverse items for all three outcomes. Because of interitem correlations smaller than .70 (Rammstedt et al., 2017), we cannot guarantee that there is an acquiescence problem. However, internal consistencies of all measures, item statistics, and factor analyses were acceptable. Moreover, our findings are limited to a small sample of 101 LTP in Germany. It would be valuable to replicate our findings on the relationship between triggers, needs, and the observed effects of threat on outcomes in other organizational contexts in various countries with a larger sample of LTP.

Further, some random data measuring dysfunctional support and perceived exclusion are missing. Experts have not reached a consensus regarding at what percentage missing data become problematic (Schlomer et al., 2010). We decided to use FIML to analyze the structure of both constructs because it does not systematically over- 
estimate or underestimate regression coefficients under completely random conditions and is superior to other methods of treating missing data (Enders \& Bandalos, 2001).

Finally, our data were cross-sectional; therefore, we could investigate neither the causal relationship between threat and outcomes nor their development over time. Longitudinal studies on the relationship may be able to generate new insights about the formation of role threat and its influence on different outcomes over time.

Despite these limitations, the study replicates the results of other studies on dysfunctional support in a new work context. Because of the similarity of the measuring instruments to those used in existing work and because of the similar result patterns, the findings are a first indicator that role threat in LPT influences role identification and job satisfaction.

\section{Future Research Directions}

Future threat research should focus on the negative consequences of threat and the empirical investigation of the underlying threat mechanism. The present study indicates several implications for future research.

First, in our study, we provide evidence that dysfunctional support, as a type of disrespectful behavior, is an important trigger of LPT threat. We discussed that other work-related behaviors are also perceived as disrespectful, for instance, the decisions of others that affect the individual (e.g., Kyratsis et al., 2017). Further research should identify further behaviors by others that are perceived as disrespectful by LPT to illuminate what triggers LPT threats.

Second, in our study, we focused on perceived exclusion (need for belonging) as a mediating variable for experiencing threats and negative consequences according to theoretical assumptions (cf., Semmer et al., 2007). Further research should consider further needs (e.g., need for competence) as mediators in the relationship between triggers and negative outcomes, such as low job satisfaction.

Finally, future research should consider some contextual as well as work- and task-related factors as moderators.

Sex of the LPT. We already mentioned the possible moderating effect of sex on LPT threats. Even though post hoc analyses of our data did not provide any gender differences in dysfunctional support and the perception of being excluded ${ }^{2}$, gender stereotyping of LPT should be a topic in future research. Rudman and Mescher (2013) indicate that men are confronted with female stereotypes (e.g., being weak and more communal) when they take on traditional female roles such as childcare. This might be the reason why they receive dysfunctional support just like female LPT. Furthermore, gender stereotypes indicate that men and women are differently sensitive to specific needs (men: need for status, women: need for inclusion; cf. Ellemers, 2017).

Motive for LPT. Individual motives for becoming LPT are diverse (e.g., childcare, advanced training) and may also have a variable impact on LPT threats. Depending on how much the employees empathize with the motives for the LPT working time reduction, they may react with more or less disrespectful behavior (cf. Horvath et al., 2018). Additionally, motives may influence LPT need sensitivity (Kanfer et al., 2017). For example, LPT who choose the part-time leadership model to take care of their children might have a stronger need for belonging than those who choose the working-time leadership model for developing their leadership skills in an MBA program after work. The latter type of LTP might have a stronger need for competence than an LPT who chooses the model to have time for childcare. However, post hoc analyses of our data confirmed the influence of motives neither on the perception of dysfunctional support nor on perceived exclusion ${ }^{3}$.

Extent of LPT. Furthermore, the range of working-time reduction may also influence LPT threats. Research indicates that negative expectations toward the new working-time model of leaders are the main cause of dysfunctional supportive behavior (cf. Moldzio et al., 2016). This means the more LPT reduce their working time and the more their working-time model deviates from the traditional full-time-leadership model, the more LPT may experience dysfunctional support. Post hoc analyses confirm this assumption by indicating that the extent of working time reduction relates to the extent of dysfunctional support. Here, we also found a positive correlation between the extent of working time reduction and perceived exclusion. ${ }^{4}$ Therefore, needs also seem to be influenced by the extent of the reduction.

\footnotetext{
The Mann-Whitney $U$-Test for group differences was not significant for dysfunctional support, $U=810.00, Z=-.08, p=.938$, and perceived exclusion, $U=797.00, Z=-.42, p=.672$.

3 The Kruskal Wallis $\mathrm{H}$-Test for group differences was not significant for dysfunctional support, $H(5)=4.31, p=.506$, and perceived exclusion, $H(5)$ $=7.77, p=.169$.

4 Pearson correlations indicate a positive relationship between the extent of working time reduction of dysfunctional support, $r=.42, p<.001$, and perceived exclusion, $r=.40, p<.001$.
} 
Level of LPT. How management colleagues deal with LPT may also influence LPT threats. Research indicates that LPT benefit from support by colleagues from other hierarchical levels, for example, when scheduling meetings in the way that LPT can participate (Gärtner et al., 2016). Thus, LPT are more present so that, on the one hand, subordinates have fewer reasons to fear that they will be overloaded; on the other hand, LPT themselves feel less excluded and are less vulnerable to accusations like "You are never there." However, explorative analyses of our data did not confirm that LPT with responsibilities at low, middle, or high leadership levels differ in dysfunctional support and perceived exclusion ${ }^{5}$.

LPT Span of Control. The span of control, i.e., the number of subordinates for whom the LPT are responsible, may influence LPT threats. Especially in small teams, employees are faced with increasing work pressure, since tasks are always delegated to the same people, and the work is distributed to fewer subordinates (Jochmann-Döll, 2017). However, post hoc analyses of our data did not confirm that span of control is related to dysfunctional support or perceived exclusion. ${ }^{6}$ Our sample includes a wide range of control span (see participants and procedure), therefore, we apply for future research on this topic.

\section{Practical Implications}

Three practical implications can be derived from the study which are linked to (1) LPT-relevant triggers and (2) need-based expectations as a leader.

First, to avoid threats to LPT, organizations should create an environment and culture where triggers based on being an LPT do not occur. The working-time leadership model should be implemented in a task-oriented and functional manner. The necessary task analysis, job allocation, and prognostic evaluation aim to clarify the organizational tasks and roles of subordinates and management colleagues (Ellwart et al., 2015). This clarification includes, among other things, clear agreements on the definition and delegation of tasks, objectives, and representation rules (Karlshaus \& Kaehler, 2017). Therefore, followers' participation in the change from full-time leadership to LPT may be central to overcoming resistance to LPT (e.g., Fernandez \& Rainey, 2006). Thus, unrealistic expectations and the resulting cynicism of subordinates may be avoided (Bessing et al., 2017).
Additionally, organizations should create an environment and culture that supports the success of LPT through respect, professionalism, and continuous enhancement, so that the leader-related stereotypes of subordinates, such as "A good leader is omnipresent" (e.g., Melchers \& Zölch, 2001) would likely be unrealistic.

Second, the individual expectations and needs of LPT, the evaluation by LPT of potential triggers, and the search by LPT for resources to protect and support their own role provide useful perspectives for organizational human resource management as well as for the individual leader. With a massively changed working-time schedule because of family or other obligations, roles, and role expectations inevitably change. LPT have to reflect their expectations and needs in new leadership situations (Jochmann-Döll, 2017). Since triggers must be perceived as threatening, another approach is to influence the perception and evaluation of potential triggers in practice (cf., Petriglieri, 2011). Even though avoiding self-threatening evaluation (coping) has its limitations, studies that present the organizational and clinical context show that people differ in their perception and evaluation of triggers. For example, the study by Meier and Semmer (2018) found that leaders and subordinates differ in their evaluation regarding the illegitimacy of the same tasks.

\section{Conclusion}

The study transferred the theoretical concept of SOS (Semmer et al., 2007, 2019) to the context of LPT. The results provide empirical evidence for the threat mechanism based on the interplay of triggers and frustrated needs. In addition to these theoretical contributions, it offers approaches for the practical risk management of LPT.

\section{References}

Alberternst, C., \& Moser, K. (2007). Vertrauen zum Vorgesetzten, organisationales Commitment und die Einstellung zum Mitarbeitergespräch [Trust in supervisor, organizational commitment and attitudes towards employee development interviews]. Zeitschrift für Arbeits- und Organisationspsychologie A\&O, 51(3), 116-127. https://doi.org/10.1026/0932-4089.51.3.116

Allen, T. D., \& Russel, J. E. (1999). Parental leave of absence: Some not so family-friendly implications. Journal of Applied Social Psychology, 29, 166 -191. https://doi.org/10.1111/j.1559-1816. 1999.tb01380.x

Beals, K. P., \& Peplau, L. A. (2005). Identity support, identity devaluation, and well-being among lesbians. Psychology of

\footnotetext{
The Kruskal Wallis H-Test for group differences was not significant for dysfunctional support, $H(2)=.97, p=.616$, and perceived exclusion, $H(2)$ $=.79, p=.675$.

Pearson correlations indicate no relationship between the LPT span of control and dysfunctional support, $r=.15 ., p=.070$, and perceived exclusion, $r=.01, p=.410$
} 
Women Quarterly, 29(2), 140-148. https://doi.org/10.1111/j. 1471-6402.2005.00176.x

Beehr, T. A., Bowling, N. A., \& Bennett, M. M. (2010). Occupational stress and failures of social support: When helping hurts. Journal of Occupational Health Psychology, 15(1), 45-59. https://doi.org/10.1037/a0018234

Bessing, N., Gärtner, M., \& Schiederig, K. (2017). Reduzierte Arbeitszeit in Führungspositionen: Empirische Befunde und Erfolgsfaktoren in der 360-Grad-Perspektive [Reduced working hours in leadership positions: Empirical findings and success factors in a 360-degree perspective]. In A. Karlshaus \& B. Kaehler (Eds.), Teilzeitführung. Rahmenbedingungen und Gestaltungsmöglichkeiten in Organisationen [Part-time leadership. Conditions and implementation options in organizations] (pp. 83-100). Springer Gabler. https://doi.org/10.1007/978-3-658-07055-7_6

Blincoe, S., \& Harris, M. J. (2011). Status and inclusion, anger and sadness: Gendered responses to disrespect. European Journal of Social Psychology, 41(4), 508-517. https://doi.org/10.1002/ ejsp.811

Borghardt, L. (2012). Der geteilte Chefposten [The shared leadership position]. Wirtschaftswoche. Retrieved from http://www. wiwo.de/erfolg/management/management-der-geteilte-chef posten/6900164.html

Brett, J. M., \& Stroh, L. K. (2003). Working 61 plus hours a week. Why do managers do it? Journal of Applied Psychology, 88(1), 67 - 78. https://doi.org/10.1037/0021-9010.88.1.67

Burnette, J. L., Pollack, J. M., \& Hoyt, C. L. (2010). Individual differences in implicit theories of leadership ability and self-efficacy: Predicting responses to stereotype threat. Journal of Leadership Studies, 3(4), 46-56. https://doi.org/10.1002/jls.20138

Coyle, J. (1999). Exploring the meaning of "dissatisfaction" with health care: The importance of "personal identity threat." Sociology of Health \& Illness, 21(1), 95-123. https://doi.org/ 10.1111/1467-9566.t01-1-00144

Cropley, M., Michalianou, G., Pravettoni, G., \& Millward, L. (2012). The relation of post work ruminative thinking with eating behaviour. Stress and Health, 28, 23-30. https://doi.org/10. 1002/smi.1397

Dimitrov, D. M. (2010). Testing for factorial invariance in the context of construct validation. Measurement and Evaluation in Counseling and Development, 43(2), 121-149. https://doi.org/ $10.1177 / 0748175610373459$

Drennan, J. (2003). Cognitive interviewing: Verbal data in the design and pretesting of questionnaires. Journal of Advanced Nursing, 42(1), 57 -63. https://doi.org/10.1046/j.1365-2648. 2003.02579.x

Ebaugh, H. R. F. (1988). Becoming an ex: The process of role exit. University of Chicago Press.

Ellemers, N. (2017). Gender stereotypes. Annual Review of Psychology, 69, 275 - 298. https://doi.org/10.1146/annurev-psych$122216-011719$

Ellwart, T., Russell, Y., \& Blanke, K. (2015). Führung als Doppelspitze: Co-Leitung erfolgreich managen [Dual leadership. successful management of co-leadership]. In R. v. Dick \& J. Felfe (Eds.), Handbuch Mitarbeiterführung, Wirtschaftspsychologisches Praxiswissen für Fach- und Führungskräfte (pp. 251-262). Springer. https://doi.org/10.1007/978-3642-55213-7_44-1

Elprana G., Hernandez A., \& Pundt L. (2016). Frauen in Führungspositionen [Women in leadership positions]. In Felfe J. \& van Dick R. (Eds.), Handbuch Mitarbeiterführung [Employee Management Handbook] (pp. 185-197). Springer. https://doi.org/ 10.1007/978-3-642-55080-5_23

Enders, C. K., \& Bandalos, D. L. (2001). The relative performance of full information maximum likelihood estimation for missing data in structural equation models. Structural Equation Model- ing, 8(3), 430-457. https://doi.org/10.1207/S15328007SEM 0803_5

Fernandez, S., \& Rainey, H. G. (2006). Managing successful organizational change in the public sector. Public Administration Review, 66(2), 168-176. https://doi.org/10.1111/j.15406210.2006.00570.x

Flanagan, J. (2015). Gender and the workplace: The impact of stereotype threat on self-assessment of management skills of female business students. Advancing Women in Leadership, 35 , $166-171$.

Gärtner, M., Garten, T., \& Husmann, M. (2016). Flexible Arbeitsmodelle für Führungskräfte. Zum Stand der Forschung [Flexible work models for leaders. State of Research]. Zeitschrift für Arbeitswissenschaft, 70(4), 220-230. http://link.springer.com/ article/10.1007/s41449-016-0038-3

Hayes, A. F. (2013). An introduction to mediation, moderation, and conditional process analysis. Guilford.

Herzberg, F. (1972). One more time: How do you motivate employees. In L. E. Davis \& J. C. Taylor (Eds.), Design of jobs: Selected readings (pp. $113-125)$. Penguin.

Hipp, L., \& Stuth, S. (2013). Management und Teilzeit? Eine empirische Analyse zur Verbreitung von Teilzeitarbeit unter Managerinnen und Managern in Europa [Being a part-time manager? An empirical analysis of the use of part-time work among managers in Europe]. Kölner Zeitschrift für Soziologie und Sozialpsychologie, 65(1), 101-128. https://doi.org/10. 1007/s11577-013-0193-x

Horvath, L. K., Grether, T., \& Wiese, B. S. (2018). Fathers' realizations of parental leave plans: Leadership responsibility as help or hindrance? Sex Roles, 79, 163 - 175. https://doi.org/10.1007/ s11199-017-0861-9

Hu, L. T., \& Bentler, P. M. (1999). Cutoff criteria for fit indexes in covariance structure analysis: Conventional criteria versus new alternatives. Structural Equation Modeling, 6(1), 1-55. https:// doi.org/10.1080/10705519909540118

Jochmann-Döll, A. (2017). Praxisbeispiel Polizei: Eine Frage der Balance [Case study Police: A question of balance]. In A. Karlshaus \& B. Kaehler (Eds.), Teilzeitführung. Rahmenbedingungen und Gestaltungsmöglichkeiten in Organisationen [Parttime leadership. Conditions and implementation options in organizations] (pp. 207-219). Springer Gabler.

Kanfer, R., Frese, M., \& Johnson, R. E. (2017). Motivation related to work: A century of progress. Journal of Applied Psychology, 102(3), 338 - 355. https://doi.org/10.1037/apl0000133

Karlshaus, A., \& Kaehler, B. (Eds.). (2017). Teilzeitführung: Rahmenbedingungen und Gestaltungsmöglichkeiten in Organisationen [Part-time leadership. Conditions and implementation options in organizations]. Springer-Verlag.

Kline, R. B. (2011). Principles and practice of structural equation modeling. Guilford.

Koenig, A. M., Eagly, A. H., Mitchell, A. A, \& Ristikari T (2011) Are leader stereotypes masculine? A meta-analysis of three research paradigms. Psychological Bulletin, 137(4), 616-642. https://doi.org/10.1037/a0023557

Kurtessis, J. N., Eisenberger, R., Ford, M. T., Buffardi, L. C., Stewart, K. A., \& Adis, C. S. (2017). Perceived organizational support: A meta-analytic evaluation of organizational support theory. Journal of Management, 43, 1854-1884. https://doi. org/10.1177/0149206315575554

Kyratsis, Y., Atun, R., Phillips, N., Tracey, P., \& George, G. (2017). Health systems in transition: Professional identity work in the context of shifting institutional logics. Academy of Management Journal, 60(2), 610-641. https://doi.org/10.5465/amj.2013.0684

Leary, M. R., \& Baumeister, R. F. (2000). The nature and function of self-esteem: Sociometer theory. Advances in Experimental 
Social Psychology, 32, 1 -62. https://doi.org/10.1016/S00652601(00)80003-9

Maznevski, M. L., Stahl, G. K., \& Mendenhall, M. E. (2013). Toward an integration of global leadership practice and scholarship: Repairing disconnects and heightening mutual understanding. European Journal of International Management, 7(5), 493-499.

Meier, L. L., \& Semmer, N. K. (2018). Illegitimate tasks as assessed by incumbents and supervisors: converging only modestly but predicting strain as assessed by incumbents, supervisors, and partners. European Journal of Work and Organizational Psychology, 27(6), 764-776. https://doi.org/10.1080/1359432X. 2018.1526785

Melchers, F., \& Zölch, D. (2001). Führungskräfte in Teilzeitarbeit. Beweggründe, Arbeitsorganisation, Kommunikation [Leadership in part-time. Motivations, work organization, communication]. In E. Ulich (Ed.) Beschäftigungswirksame Arbeitszeitmodelle [Employment-effective working time models] (pp. 331 351). vdf Hochschulverlag AG an der ETH.

Meyenberg, C., \& Schinner, C. (2017). Praxisbeispiel TUI Deutschland GmbH: Der Weg von der Anwesenheits- zur Performancekultur [Case study: TUI Deutschland GmbH: The path from an culture of attendance to a performance]. In A. Karlshaus \& B. Kaehler (Eds.), Teilzeitführung. Rahmenbedingungen und Gestaltungsmöglichkeiten in Organisationen [Part-time leadership. Conditions and implementation options in organizations] (pp. 207 -219). Springer Gabler.

Miller, K. I., \& Monge, P. R. (1986). Participation, satisfaction, and productivity: A meta-analytic review. The Academy of Management Journal, 29(4), 727 - 753. https://doi.org/10.5465/255942

Moldzio, T., \& Ellwart, T. (2017). Führung in reduzierter Arbeitszeit: Attraktives Leitungsmodell zwischen Akzeptanz und Abneigung [Leadership in reduced working hours: Attractive leadership model between acceptance and aversion]. Perspektiven 5-6/ 2017, $38-40$.

Moldzio, T., Ellwart, T., Hofer, A., Burkhart, E. M., Endres, E. C., Henn, S., Kaup, C. G., Merz, S., \& Rynek, M. (2016). Führen in reduzierter Arbeitszeit: Chancen und Risiken für die Personalarbeit der Zukunft [Leadership in reduced working time: Opportunities and risks for human resources in the future]. Wirtschaftspsychologie aktuell, 2016(1), 13-16.

Muller, D., \& Butera, F. (2007). The focusing effect of selfevaluation threat in coaction and social comparison. Journal of Personality and Social Psychology, 93(2), 194-211. https://doi. org/10.1037/0022-3514.93.2.194

Muthén, L. K., \& Muthén, B. O. (1998-2014). Mplus User's Guide (7 th ed.). Author.

Nielsen, K., Nielsen, M.B., Ogbonnaya, C., Känsälä, M., Saari, E., \& Isaksson, K. (2017). Workplace resources to improve both employee well-being and performance: A systematic review and meta-analysis. Work \& Stress, 31(2), $101-120$. https://doi. org/10.1080/02678373.2017.1304463

Petriglieri, J. L. (2011). Under threat: Responses to and the consequences of threats to individuals' identities. Academy of Management Review, 36(4), 641-662. https://doi.org/15.11. 201810.5465/amr.2009.0087

Preacher, K. J., \& Hayes, A. F. (2004). SPSS and SAS procedures for estimating indirect effects in simple mediation models. Behavior Research Methods, Instruments, \& Computers, 36(4), 717 731. https://doi.org/10.3758/BF03206553

Preacher, K. J., \& Hayes, A. F. (2008). Asymptotic and resampling strategies for assessing and comparing indirect effects in multiple mediator models. Behavior Research Methods, 40(3), 879 - 891. https://doi.org/10.3758/BRM.40.3.879

Rammstedt, B., Danner, D., \& Bosnjak, M. (2017). Acquiescence response styles: A multilevel model explaining individual-level and country-level differences. Personality and Individual Differences, 107, 190-194. https://doi.org/10.1016/j.paid.2016.11.038

Rudman, L. A., \& Mescher, K. (2013). Penalizing men who request a family leave: Is flexibility stigma a femininity stigma? Journal of Social Issues, 69(2), 322-340. https://doi.org/10.1111/josi. 12017

Sam, C. H. (2012). Part-time and full-time faculty conceptualizations of academic community: A case study. University of Southern California.

Schlomer, G. L., Bauman, S., \& Card, N. A. (2010). Best practices for missing data management in counseling psychology. Journal of Counseling Psychology, 57(1), 1-10. https://doi.org/10. 1037/a0018082

Schmidt-Atzert, L., \& Amelang, M. (2012). Psychologische Diagnostik [Psychological diagnostics]. Springer.

Semmer, N. K. (2010). Im Prinzip altbekannt, im Detail kaum erforscht: Die Bedeutung von Selbstwertbedrohung und Selbstwertbestätigung für die arbeitspsychologische Stress- und Gesundheitsforschung [In general well known, in detail rarely examined: The importance of self-esteem threat and selfesteem affirmation for occupational psychological stress and health research]. Lecture at the Institute of Psychology, University of Trier.

Semmer, N. K., Elfering, A., Jacobshagen, N., Perrot, T., Beehr, T. A., \& Boos, N. (2008). The emotional meaning of instrumental social support. International Journal of Stress Management, 15(3), 235-251. https://doi.org/10.1037/1072-5245.15.3.235

Semmer, N. K., Jacobshagen, N., Meier, L. L., \& Elfering, A. (2007). Occupational stress research: The "stress-as-offense-to-self" perspective. In J. Houdmont \& S. McIntyre (Eds.), Occupational health psychology: European perspectives on research, education, and practice (Vol. 2, pp. 43 -60). ISMAI.

Semmer, N. K., Tschan, F., Jacobshagen, N., Beehr, T. A., Elfering, A., Kälin, W., \& Meier, L. L. (2019). Stress as offense to self: A promising approach comes of age. Occupational Health Science, 3, 205-238.

Sluss, D. M., van Dick, R., \&, Thompson, B. S. (2002). Role theory in organizations: A relational perspective. In S. Zedeck (Ed.), APA handbook of industrial and organizational psychology (Vol. 1, pp. 505 -534). American Psychological Association.

Stocker, D., Jacobshagen, N., Krings, R., Pfister, I. B., \& Semmer, N. K. (2014). Appreciative leadership and employee well-being in everyday working life. German Journal of Human Resource Management, 28(1-2), 73-95. https://doi.org/10.1177/ 239700221402800105

Stocker, D., Jacobshagen, N., Semmer, N. K., \& Annen, H. (2010). Appreciation at work in the Swiss armed forces. Swiss Journal of Psychology/Schweizerische Zeitschrift für Psychologie/Revue Suisse de Psychologie, 69(2), 117-124. https://doi.org/10. 1024/1421-0185/a000013

Stuth, S., \& Hipp, L. (2017). Führung in Teilzeit? Eine empirische Analyse zur Verbreitung von Teilzeitarbeit unter Führungskräften in Deutschlang und Europa [Leadership in part-time? An Empirical analysis on the prevalence of part-time work among leaders in in Germany and Europe]. In A. Karlshaus \& B. Kaehler (Eds.), Teilzeitführung. Rahmenbedingungen und Gestaltungsmöglichkeiten in Organisationen [Part-time leadership. Conditions and implementation options in organizations] (pp. 31 43). Springer Gabler.

Unanue,W., Gómez, M. E., Cortez, D., Oyanedel, J. C., \& MendiburoSeuguel, A. (2017). Revisiting the link between job satisfaction and life satisfaction: The role of basic psychological needs. Frontiers in Psychology, 8, 1 - 17. https://doi.org/10.3389/fpsyg. 2017.00680

Vahle-Hinz, T., Baethge, A., \& Van Dick, R. (2019). Beyond one workday? A daily diary study on causal and reverse effects 
between experienced workplace incivility and behaving rude toward others. European Journal of Work and Organizational Psychology, 28(2), 272-285. https://doi.org/10.1080/1359432 X.2019.1576633

Wayne, J. H., \& Cordeiro, B. L. (2003). Who is a good organizational citizen? Social perception of male and female employees who use family leave? Sex Roles, 49, 233 -246. https://doi.org/10. 1023/A:1024600323316.

Weiss, D.J., Dawis, R.V., England, G.W., Lofquist, L.H. (1967). Manual for the Minnesota satisfaction questionnaire. Industrial Relations Center, University of Minnesota.

\section{History}

Received February 9, 2020

Revision received September 18, 2020

Published online July 29, 2021

\section{Funding}

Open access publication enabled by Trier University.

\section{ORCID}

Mona Rynek

(iD) https://orcid.org/0000-0003-2842-430X

\section{Mona Rynek}

Department of Psychology

Trier University

54286 Trier

Germany

rynek@uni-trier.de 